\title{
Rescuing the Media in Emerging Democracies through ICT
}

\section{Jose Ortiz}

Business School

University of Auckland

Auckland, New Zealand

Email: j.ortiz@auckland.ac.nz

\section{Abstract}

Several studies have shown the efficiency and pitfalls of ICT for mediating collective communication during political upheavals. However, little literature exists on understanding how the diversity of content generated through ICT empowers a free press when traditional media channels fail to expose the truth and promote public debate. This research aims to broaden our understanding of how ICT facilitate the exposure and interpretation of conditions in government institutions that go against public moralities - interpretations with the potential to mobilise thousands of individuals to protest. We engaged in an in-depth qualitative research using data from the Twittersphere. We conducted our study in the context of a Guatemalan tragedy in which 41 girls living in a state care home lost their lives. Our contribution to the literature is the understanding of how ICT enables the collective construction of meaning powerful enough to mobilise thousands of individuals in protest.

Keywords Twitter, social media, crowd protest, democracy, alternative media 


\section{Introduction}

The media is often regarded as the fourth institution in modern democratic states along with the legislative, judiciary and executive. A core function of the media is to identify dysfunctions in any of the other three institutions by exposing conditions that go against public morality (Miranda et al. 2016). In democratic regimes, the media constitute a "viable base from which to stand up to government and concentrated corporate power" (Miranda et al. 2016, p. A3). They serve a democratisation function (Miranda et al. 2016) by enabling spaces for the rational exchange of views about matters of public interest - views that are free from the control of any authority and that can in principle be critical of the state (Habermas 1991).

Nonetheless, the reality of many emerging democracies is that the media are often subject to the question of whether they act as "guardian of the public sphere or lap dog of the power elite" (Blankson and Murphy 2012, p. 1). In Latin America, numerous governments have forged mutually beneficial relationships with national media companies that paved the way for the development of strong media monopolies (Fox and Waisbord 2002). In Central America, monopolistic television industries have not only remained absent from debate on government policy but also engaged in actions to crush views against state institutions or business elites (Rockwell and Janus 2001).

In contrast to the 1990 os where technological innovations contributed to the concentration of media ownership across Latin America, the adoption of information and communication technology (ICT) during the 2000s has turned the table for media monopolies. Recent social uprisings mediated by ICT against dysfunctional state institutions and corrupt practices by government executives have shed light on the battle for rescuing the media from its co-optation by information monopolies. Several studies in the IS literature have shown how ICT upgrades the organizational functioning of activist groups with political agendas by strengthening the ties with their followers (Selander and Jarvenpaa 2016), potentially helping them to reach a broader audience (Starbird and Palen 2012) and achieve human emancipation (Leong et al. 2015; Young 2017). However, there is little understanding on how the diversity of content generated through ICT empowers a free press when traditional media channels fail to expose the truth and promote public debate.

The problem is that legitimate criticism of the government involves different activities and the participation of diverse actors in society. Activities such as the reporting of dysfunctional state institutions and the mobilisation of citizens to protest are two distinct processes carried out by different social actors, but their impact on strengthening democracy is deeply intertwined. The reporting of dysfunctional state institutions affects perceptions of public authorities. At the same time, the shared interpretation of certain conditions and behaviours can unleash crowd protests against the government in demand for social justice and an end to vicious practices.

In view of the alternatives brought by ICT for accessing information when monopolies control traditional media channels (e.g., television broadcasting), we want to investigate how ICT enable spaces for the exposure and interpretation of conditions in government institutions that break with values and norms in society - interpretations with the potential to mobilize thousands of individuals to protest. Hence, the research question we seek to answer in this paper is: How does the exposure and interpretation of dysfunctional state institutions through ICT lead to the organising of crowd protests?

To answer our research question, we conducted a qualitative case study of a Guatemalan tragedy in which 41 girls lost their lives while living in a care home operated by the government. We adopted the interpretive case study methodology (Klein and Myers 1999) to analyse the Twitter communications that unfolded in the aftermath of the tragedy. Our contribution to the literature is the understanding of how ICT enables the collective construction of meaning powerful enough to mobilise thousands of individuals in protest.

This paper proceeds as follow. In the next section, we expand on the evolution of the media in emerging democracies in Latin America. In Section 3, we establish our theoretical foundations drawing on Lievrouw (2011's theory of alternative media. We present the research method and analysis from our analysis of the ICT-enabled communications in Section 4. In Sections 5 and 6, we present our findings and discuss how the interpretation of the tragedy led to the organising of several crowd protests in the Guatemalan society. We conclude with limitations and directions for future research.

\section{The Evolution of the Media in Latin America}

Two parallel forces, local politics and the globalisation of media markets, have shaped the development of Latin American media since the 1990s (Fox and Waisbord 2002). On the side of local politics, the 
military dictatorships that swept Latin America in the 1970s stimulated the growth of the media industry while exercising tight political control. In the early to mid-1980s, the replacement of military dictatorships by civilian rule marked the beginning of a fresh and promising democratic era. However, the much hoped-for transition to democracy did not bring genuine independence to the media as an institution. Government executives in many of the new democratic regimes forged mutually beneficial relationships with broadcasting industries that paved the way for the emergence of strong media monopolies.

During the 1990s, the globalising push furthered the adoption of technological innovations that had a significant impact on the restructuration of the media industry (Fox and Waisbord 2002). The general evolution of technology and media industries in Latin America resulted in the rapid growth of radio and television, the rise of new forms of distribution of TV programming (cable and satellite), and the decline in newspaper readership. For media companies with ambitious domestic and global goals, having a solid position in the television industry was crucial: "over-the-air television receives the lion's share of advertising revenue" (Fox and Waisbord 2002, p. 11).

Practices of clientelism deeply rooted since the days of military dictatorships and the widespread adoption of technology during the globalisation process were the catalysts for a process of rapid concentration of information resources (Fox and Waisbord 2002). Today, Latin American governments may no longer own broadcasting stations, as in past decades of civil war and authoritarianism, but they are still able to influence the conditions under which media businesses operate. Domestic policies favouring media corporations and the enormous size of domestic markets explain why Mexico and Brazil today have the two largest, monopolistic, and politically powerful broadcasting industries in the Western Hemisphere.

The formation and prevalence of money-spinning media monopolies across Latin America occurred at the expense of trading their public service role for one that returned more profits (Fox and Waisbord 2002). Attempts at media policies by Latin American states were largely successful when motivated by the need for increased political control of the media but largely unsuccessful when motivated by considerations of public services and national culture (Waisbord 1995).

In Central America, media monopolies represent powerful anti-democratic forces that have prevented free expression from a multiplicity of viewpoints (Rockwell 2007). In contrast to Brazil and Mexico, television monopolies and quasi-monopolies in Central America were financed by regional media companies and foreign investors that leveraged cultural proximity to make inroads in medium-size and small countries (Fox and Waisbord 2002). As a result, monopolistic television industries in Central America have neglected a tradition of public service and an ethical path in strengthening democracy (Rockwell 2007).

In Guatemala, a broadcasting monopoly started with the acquisition of a television network in 1981 by a Mexican investor. During the 1990s, the Mexican mogul, following the scheme developed in Mexico of catering the political class, acquired all major television channels and a significant slice of the radio spectrum in Guatemala (Rockwell and Janus 2001). Since then, the commercial television monopoly in Guatemala has not only purged voices critical of the central government but also used to attack media outlets not aligned with government policies (Rockwell 2007).

The television monopoly and oppressing tactics developed during a brutal civil war fought between the Guatemalan government and leftist rebel groups created a culture of silence - a culture that prevented journalism in Guatemala from "criticizing the government, the army, or even some of the country's leading businessmen" (Rockwell and Janus 2001, p. 497). Through the early 2000s, the television monopoly in Guatemala acted as a force that undermined the fundamental democratic concept of allowing journalists and others in society to counter government action through critical ideas offered through free and open discussion (Rockwell and Janus 2001).

\section{Theoretical Framework}

In this paper, we argue that contrary to the technological innovations during the 1990 s that boosted the concentration of information resources across Latin America, the adoption of Internet technologies during the 2000s has turned the table for media monopolies. The powerful media monopolies still exist, of course, but their dominance is no longer assured as it was during the 1990s, as the widespread adoption of the Internet creates unprecedented opportunities for expression and interaction. Activists, political and cultural groups across Latin America have found Internet technologies to be inexpensive, powerful tools for challenging the givens of anti-democratic monopolistic systems that have long dominated the media. 
Echoing the waves of social and political unrest unleashed by ICT at a global stage in the last decade, Internet-empowered societies in Latin America have also come together to protest against impunity, negligence and corruption practices in the government. A novel characteristic that personifies this upsurge of political struggle is the decentralisation of information resources. With the advancement of the Internet, new forms of activist-produced media have been critical in the mobilisation of thousands of citizens in massive crowd protests. In Guatemala for example, Twitter has been central for disseminating information and organising people to take collective action in unprecedented demonstrations against corruption in the government (Harlow and Harp 2012; LeBrón 2009).

In this paper, we focus in how the exposure and interpretation of dysfunctional state institutions through Twitter lead to the organising of crowd protests. We focus on the democratic principle that every citizen has "a voice that can and should be heard" (Kunreuther 2013, p. 1). In the context of democratic regimes that have long-silenced critical views against those in power, crowd protests become the primary mode to break the silence and drive political change (Terchek 1974). Without the conventional capabilities necessary to gain access to the political system and affect change there, "the powerless rely on unorthodox measures to create disorder and thereby apply pressure" on public authorities (Terchek 1974, p. 133). People act collectively rather than singly because "they believe that there is strength in numbers" (Kendall 2012, p. 601).

Several streams in the literature have theorised effects of ICT, particularly social media, in organising collective action in the form of crowd protests (Flanagin et al. 2006; Lievrouw 2011; Oh et al. 2015). In this paper, we draw on the theory of alternative media proposed by Lievrouw (2011 as the theoretical lens to analyse the organising of crowd protests through Twitter. Accordingly, Lievrouw (2011's perspective provides the analytical lens for studying the "current rise and diversity of activist media projects in the information age" (Wolfson 2012).

Lievrouw (2011, p. 19) defines alternative media as projects or groups that employ ICT to "challenge or alter dominant, expected, or accepted ways of doing society, culture, and politics." Their creators take advantage of the networked nature of the Internet and the ubiquity and interactivity of ICT to critique and intervene in prevailing social, cultural, and political conditions. Alternative media projects seek to be faithful to a community's values and experiences and independent of the interests of political and business elites in a way that departs from most media corporations and monopolies (Atton 2004). An important aspect of alternative media projects is that they "do not only reflect or critique mainstream media and culture, they also constitute and intervene in them" Lievrouw (2011, p. 19).

Lievrouw (2011 develops a five-part typology for differentiating five genres of alternative media - culture jamming, alternative computing (hacktivism), critical journalism (which she calls participatory journalism), mediated mobilisation, and commons knowledge. Lievrouw (2011, p. 69) outlines a framework based on common themes in social movements to explain features across the five genres of alternative media. At the most general level, three major themes link social movements and alternative media: the scope of alternative media projects; the stance of movements and projects relative to dominant society and culture; and the nature of projects as action and activists as agents of change. In this paper, we focus on the critical journalism and mediated mobilisation genres.

\subsection{Critical Journalism}

Critical journalism consists of media groups with perspectives that are often critical of the status quo in society, culture, and politics (Atton 2004, p. ix; Fuchs 2010; Lievrouw 2011, p. 19). The rise of critical journalism stems from the failure of media corporations to act in service of society as a result for their "relentless, ever-expanding demands for profit and shifts away from straight news and critical analysis to entertainment and lifestyle coverage in attempts to woo younger audiences" (Lievrouw 2011, p. 122). In this paper, we argue that in Latin America, critical journalism projects have emerged as watchdog organisations that scrutinise state institutions, counter-attacking the censorship promoted by progovernment media monopolies.

In contrast to traditional journalism, most critical journalism projects do not adhere to a centrally approved political line (Downing 2001). The goal of critical journalism is to overcome the barriers of editorial gatekeeping by reflecting a commitment to freedom of speech in which any voice can be heard and where anyone can express their opinions (Pickard 2008). Instead of the traditional advertisingbased business model, critical journalism projects tend to adopt alternative support models, including not-for-profit foundations and crowdfunding, to support their activities (Kershaw 2008).

Linking to Lievrouw (2011's genre framework, critical journalism with respect to scope tends to be produced and hosted by small teams. This feature is attributable to the fact that few activists have access to large, reliable sources of funding and staff. Regarding stance, critical journalism act as "other spaces" 
or "counter sites" for expression. Critical journalists seek to demonstrate and exemplify new, alternative values and practices for the rest of society, out of a will to create renewed communities within an increasingly thicker social network. In terms of action and agency, critical journalists seek to interrupt or alter existing conditions, to subvert common-sense or taken-for-granted meanings and situations in society.

To sum up, critical journalism critiques and opposes the market-driven cynicism and detachment of mainstream press, adopting practices and values of professional journalism online as a method of transforming the content and production of the news, and to renew its role as a brake on the government and corporate power (Lievrouw 2011, p. 148).

\subsection{Mediated Mobilization}

Whereas critical journalism aims to change public discourse and perceptions by creating the cultural and material conditions for what activists believe will be a better society, mediated mobilization "goes a step further by using ICT as the means to mobilize social movements - collective action in which people organize and work together as active participants in social change" (Lievrouw 2011, p. 150). In the context of developing countries in Latin America, the mediated mobilisation genre encompasses a growing number of social movement organisations (SMOs) with political agendas. These groups, concerned with fighting government corruption, impunity, social injustice, and violations to human rights, rely extensively on ICT, particularly social media, for advocating their causes.

Following Lievrouw (2011's genre framework, mediated mobilisation with respect to scope is largely collaborative because it promotes collaboration among like-minding people. Collaboration takes a variety of forms, from interpersonal relationships and interaction to the creation and sharing of ideas, opinions, and information to participation in large-scale crowd protests. Regarding stance, mediated mobilisation projects act as insurgent forces existing "outside" the conventional institutions and practices of power that attempt to legitimate corrective actions to those instructions and practices. In terms of action and agency, mediated mobilisation is fundamentally interventionist in purpose. At a society-wide level, mediated mobilisation helps SMOs intervene in the workings of social and political institutions, endeavouring to change norms and values and reconfiguring the distribution of power and resources.

Mediated mobilisation aligns with studies on the use of ICT by SMOs for promoting causes of social and political change through collective action (Selander and Jarvenpaa 2016; Shirky 2011). In the context of Latin America, we focus on mediated mobilisation that promotes collective action in the form of crowd protests as a mechanism for demanding political change.

\begin{tabular}{lll}
\hline & Critical Journalism & Mediated Mobilization \\
\hline Scope & Small-scale & Shared effort \\
Stance & Counter-site for expression & Outside dominant power structures \\
Action \& Agency & Alter existing perceptions & Exercise direct action \\
\hline
\end{tabular}

Table 1. Summary of Critical Journalism and Mediated Mobilization Adapted from Lievrouw (2011

\section{Research Method}

\subsection{The Guatemalan Tragedy}

The place known as Virgen de la Asunción shelter was a care home operated by the government for the protection of children under the age of 18 who had suffered abuse or had been abandoned by their families. On March 07, 2017, about 6o children escaped after a riot broke out at the centre against alleged ill-treatment by the caregivers (The New Yorker 2017). Several hours later, police officers managed to bring the escaped children back to the shelter. On the morning of March o8, the guardians of the shelter decided to lock the protesting girls in a small classroom in the home. Chaos erupted when a fire originated inside the room, and the girls found themselves trapped inside. Reports by the Guatemalan's national police said the fire started when the girls inside the room burned mats as a means of protesting (BBC News 2017). As consequence of the fire, 19 girls perished immediately in the care home, and several more died in the coming days as consequence of high-degree burns. In total, 41 girls lost their lives as result of the fire. 
The tragic incident instigated deep feelings of dissent in the general population since the victims were all girls aged between 14 and 17 years old. Many people turned to social media channels to express their opinions, feelings, and anger at the tragedy. In the following days, the tragedy inspired the mobilisation of thousands of Guatemalans in several crowd protests. The crowd protests lasted a few weeks targeting the Guatemalan government and asking for the resignation of the Guatemalan president.

\subsection{Research Method}

We used the interpretive case study method (Klein and Myers 1999) to interpret the Twitter communications that unfolded in the aftermath of the Guatemalan tragedy. We collected and analysed Twitter data communications to explain how people interpreted the tragedy by following several key principles of interpretive case studies (Klein and Myers 1999). We adhered to the principle of hermeneutic circle according to which "human understanding is achieved by iterating between considering the independent meaning of parts and the whole that they form" (Klein and Myers 1999, p. 72). We applied the principle of hermeneutic circle by triangulating our observations with our theoretical foundations in several iterations.

In this study, we took the role of an outside observer (McKenna et al. 2017) that involved the use of web crawling software to extract user-generated data from social media platforms. We contextualised the Twitter communications in the aftermath of the Guatemalan tragedy by situating them within an ongoing process of decentralisation of information resources facilitated by ICT.

\subsection{Data Collection}

Twitter provides an Application Program Interface (API) for retrieving tweets. However, the Twitter's API imposes limitations that constrain the number of tweets that can be obtained (Jürgens and Jungherr 2016). Alternatively, tweets can be crawled directly from the Twitter's website to overcome the API's limitations. Using the Python programming language, we developed a Web crawler to collect tweets directly from the Twitter's site using the advanced search functionality provided by the website and under Twitter's privacy policy (Twitter 2018).

We collected the data using a snowball sampling approach. We first searched for tweets containing the Spanish keywords for "virgen asunción," "safe home," and seven Spanish hashtags reported by newspapers in Guatemala as trends on Twitter related to the tragedy. In total, we collected 11,682 tweets adding a total of 74,586 retweets. In addition to the tweets, we also included in our analysis news articles shared by the tweets through hyperlinks (links).

The total number of tweets collected represents an enormous volume of data, meaning that is impossible to analyse them all in a qualitative study. Thus, it is essential to rely on quantitative approaches to filter or reduce the vast amount of content (McKenna et al. 2017). We fitted the data to our a power-law distribution (Easley and Kleinberg 2010, p. 479) as a heuristic for identifying the most influential content in our data. As a result, we reduced the number of tweets from 11,862 to 372 , which is a reasonable number that we can use for qualitative analysis. The reason for such significant reduction is that many tweets in the data were retweeted a few times or not retweeted at all. In addition to the tweets, we also included in our analysis news articles shared by the tweets through hyperlinks (links).

\subsection{Data Analysis}

Following the principle of contextualization (Klein and Myers 1999), we identified types of users responsible for authoring the tweets to explain the contributions of various social actors to the interpretation of the tragedy. To define the user types, we examined the Twitter's profile and content in the timelines of each user in the dataset ${ }^{1}$. Accordingly, we identified five types: critical journalism, individual, mediated mobilisation, traditional media organisation, and journalist. Traditional media organisations consist of media outlets that also rely on means for broadcasting information invented before the Internet, such as newspapers but that do not exhibit monopolistic dominance. The alternative media groups in our analysis (critical journalism and mediated mobilisation) depend solely on ICT for the diffusion of their content. Despite being relatively new in Guatemala, these media have gained considerable status to be considered as reliable sources of information. The "individual" user role consists of users that were not identified as belonging to any of the other organisational roles. In the

${ }^{1}$ Only public profiles were examined. 
next sections, we discuss how the different types of content created by actors playing different roles contributed to the interpretation of the Guatemalan tragedy.

\section{Findings}

Initially, we identify two generic content types concerning each tweet according to its purpose: (1) factual tweets: to inform the general population about the tragedy by providing content based on facts, and (2) framing tweets: to enable individuals to identify and connect the tragedy within their daily life experiences.

\subsection{Factual Tweets}

In the context of the tragedy, the factual tweets comprise descriptions of the events that unfolded in the aftermath of the incident and reports explaining the background of the care home. Factual content are news reports that summarise the events without making judgments on those responsible or expressing sentiments of dissent.

Factual tweets were the first messages to spread through the Twittersphere, emerging before the appearance of any form of framing content. These initial tweets were posted by news media immediately after the fire in the care home. Figure 1 presents two factual tweets posted just a few moments after the fire. The tweet to the left plays a video describing the ill-treatment that girls received in the centre by one of the mothers of the victims. The tweet to the right reports the number of causalities, showing photographs of the home after the fire, including the room where the fire happened. The evidence provided in these messages in the form of photographs and videos of eyewitnesses' testimonies is an excellent example of how media organisations tap into the features of Twitter for augmenting the veracity of their tweets while avoiding rumouring and the spread of fake news.

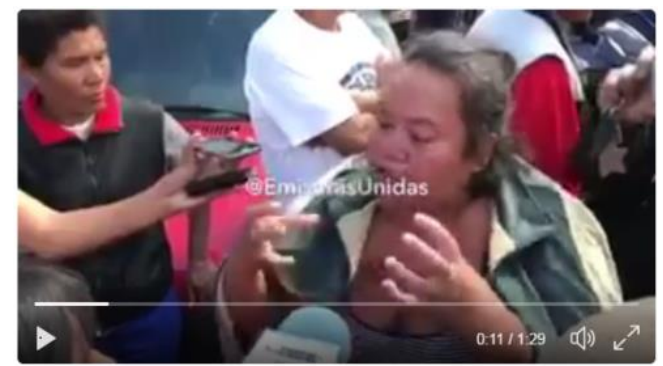

9:15 AM - 8 Mar 2017

38 Retweets 37 Likes

"Woman makes serious accusations against the personnel in charge of the care of the minors in the home Virgen de la Asunción."

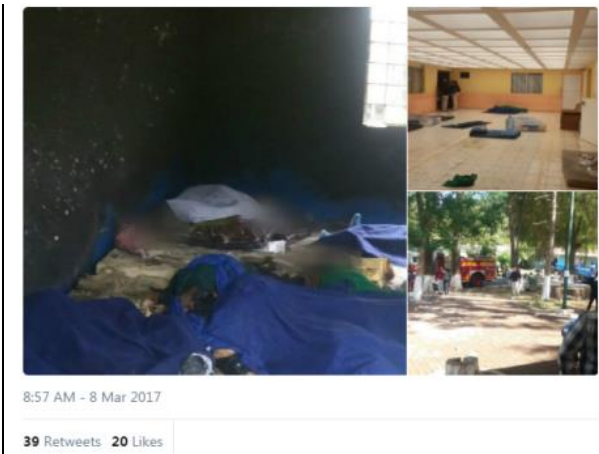

"So far, 19 people without life have been confirmed inside the home Virgen de la Asunción in San José Pinula (location of the home)."

\section{Figure 1. Example of factual tweets}

At the same time, more information regarding the living conditions of the girls at the care home came to light. Some factual presented a more in-depth story about the background of the tragedy. Figure 2 shows a tweet linking to an article ${ }^{2}$ explaining the causes of the revolt that preceded the fire. The tweet was authored by The Observer 3 , a critical journalism outlet specialising in the coverage of political and social issues in Guatemala. The linked article is strategically divided into two parts. The first part presents harrowing testimonies of sexual abuse against the minors living in the care home committed by teachers and personnel working in the centre. The victims' testimonies are accompanied by details of investigations carried out by the prosecutor's office in Guatemala that led to convictions for sexual assault against minors. The testimonies and criminal complaints described in the article go back to the year 2010, and since then, 28 charges have been filed against abuse and mistreatment of children and adolescents living in the centre. The article attributes the evils in those centres to lack of budget and the little importance that the government gives to them. The second part of the article quotes the director of the Secretary of Social Welfare of the Presidency speaking at a press conference on the same day of

${ }^{2}$ https://nomada.gt/politica/las-razones-del-amotinamiento-de-las-ninas-del-hogar-seguro/

3 A pseudonym 
the tragedy. In Figure 2, the text to the right presents an English translation of the director's statements included in the original article.

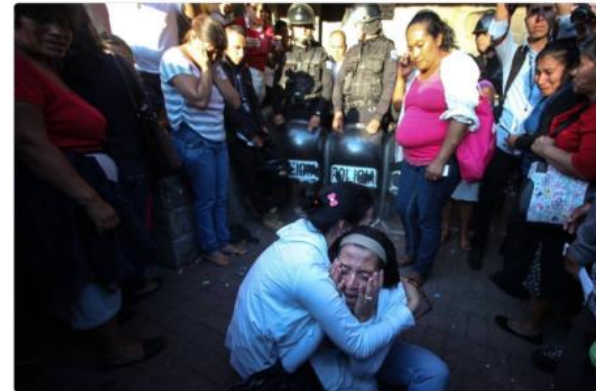

6:20 AM - 9 Mar 2017

104 Retweets 52 Likes

"You can read the article of the reasons for the revolt of the girls at the care home here." |
English translation of some statements in the linked article stated during the press conference offered by the Guatemalan government:

"The girls had sharp objects hidden in their hair. We exhausted the dialogue with the girls. We cannot accept a report that says that place is a pigsty where we torture the children. I consider the cause of the revolt, because they did not like the food, was not valid. There was no negligence. I will not present my resignation as Secretary of the Social Welfare Office. The problem is that judge mixes children who have committed crimes with children abandoned by their families. We ask the prosecutor's office to investigate, but we do not directly hold anyone responsible."

Figure 2. Example of a factual tweet with a link to an article explaining the reasons of the revolt

Figure 1 illustrates diverse forms of factual content delivered through Twitter networks, which came from traditional media organisations with online presence. However, these tweets left a big question unanswered: Why were the girls protesting? Elaborating on the possible reasons behind the riot is vital for making sense of the tragedy. Understanding the reasons that drove the girls to engage in actions that ultimately ended their lives is critical for determining how to respond to the tragedy. In this regard, Figure 2 depicts the most compelling story that answers that question. The general public extensively commented on this story on The Observer's website, and it was also published on Facebook and cited by other media outlets, both national and international.

A significant implication of the factual content type is that it provides the evidence for supporting the plausibility of future stories. As noted by Weick et al. (2005, p. 415), "stories tend to be seen as plausible when they tap into an ongoing sense of current climate and are consistent with other data." Factual tweets provided the empirical credibility for forthcoming frames because the stories they described served as empirical referents for further claims to be read as valid (Benford and Snow 2000).

\subsection{Framing Tweets}

We further discern four types of frames in our data: injustice, accusatory, mobilizer, and motivational. Whereas injustice and accusatory tweets are the outcome of efforts by social media users to render the events surrounding the tragedy as meaningful, mobilizer and motivational tweets efforts at organising ass mobilisations through explicit calls for demonstrations at different locations in Guatemala City. Table 2 presents a summary framing tweets according to their type.

\begin{tabular}{l|l|l} 
Content Type & Description & Exemplar \\
\hline Injustice & $\begin{array}{l}\text { Amplify victimisation by claiming } \\
\text { an injustice has been committed. }\end{array}$ & $\begin{array}{l}\text { "We read the name of each girl victim, her age and } \\
\text { we shout justice. \#ForTheGirls \#ItWasTheState." }\end{array}$ \\
\hline Accusatory & $\begin{array}{l}\text { Blame those perceived as } \\
\text { responsible (i.e., public } \\
\text { authorities). }\end{array}$ & $\begin{array}{l}\text { "\#ItWasTheState. For the negligence of the President } \\
\text { and the authorities of the Secretary of Social Welfare. } \\
\text { \#NationalMourning." }\end{array}$ \\
\hline Mobilizer & $\begin{array}{l}\text { Organize collective action in the } \\
\text { form of mass mobilisations. }\end{array}$ & $\begin{array}{l}\text { "We are waiting for you today in front of the } \\
\text { presidential house to remember the name of each } \\
\text { murdered girl. \#ItWasTheState." }\end{array}$ \\
\hline Motivational & $\begin{array}{l}\text { Motivate to join the mass } \\
\text { mobilisations. }\end{array}$ & $\begin{array}{l}\text { "Let's not let the horror happen as one more eye- } \\
\text { catching headline. \#ItWasTheState." }\end{array}$
\end{tabular}

Table 2. Summary of frame types

\section{Discussion}

Figure 3 quantifies the influence of each content type (in terms of retweets) and the corresponding user type. 


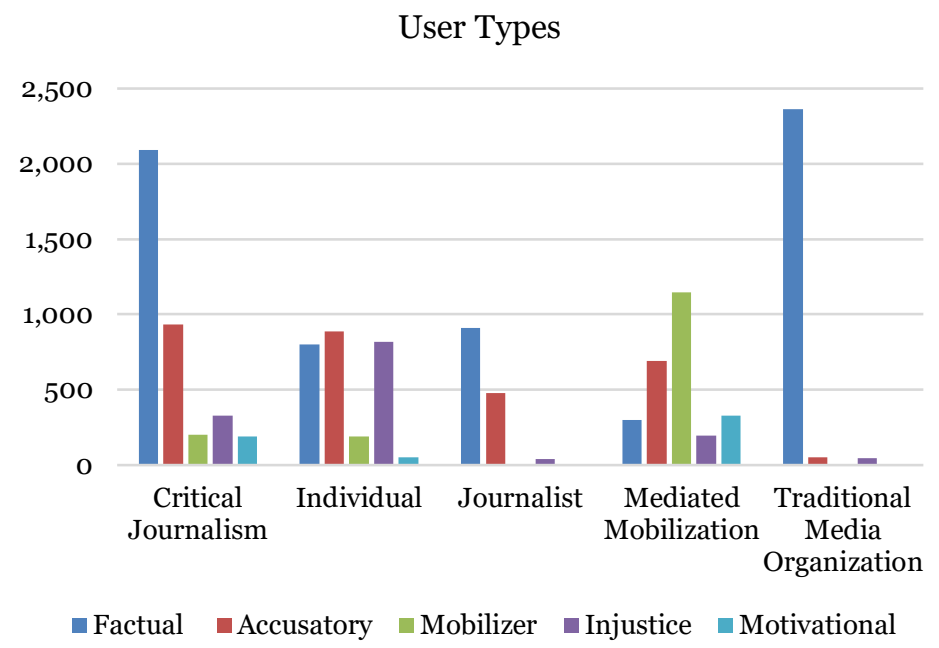

\section{Figure 3. Summary of content and user types by number of retweets}

Factual content was created mainly by both types of media organisations (traditional and alternative) and journalists. Individuals also contributed to the creation of factual content which consisted mostly of situational reports about the crowd protests like the tweet: "It was not an accident it was an execution! Shout protesters" (the tweet including also the picture of the protest). Although individuals do not typically represent reliable sources of information, when their tweets include a verifiable source, such as images or videos, it attends to the function of social media of disseminating situational information by eyewitnesses (Oh et al. 2013).

The authoring of accusatory content by alternative media organisations expresses oppositional standpoints that question the legitimacy of public authorities. The production of accusatory content bring insights that allow the general public to challenge the current system of governance (Fuchs 2010) and paves the way for collective action that aims to change prevailing political conditions (Lievrouw 2011, p. 149). Similarly, the production of factual content by alternative media attempts to transcend the filtering and censorship of news stories by information monopolies that prevent critical views of the current political system (Downing 2001, p. v). The traumatic story described in Figure 2 is an excellent example of how factual content authored by a critical journalism outlet established empirical referents for further frames that conveyed sharp criticism of public authorities.

On the other hand, SMOs were responsible for creating most of the mobilizer and motivational content, and to some extent, accusatory content. In the context of social development in Guatemala, a growing number of SMOs with political agendas and concerned with fighting government impunity and human right violations depend extensively on Twitter for advocating their causes and organising crowd protests (Harlow and Harp 2012; LeBrón 2009). Thus, the creation of mobilizer and motivational content by SMOs is consistent with literature that explain the use of ICT by activist groups in promoting causes of social change through mass mobilisations (Oh et al. 2015; Shirky 2011).

We are now able to return to our original research question viz. How does the exposure and interpretation of dysfunctional state institutions through ICT lead to the organising of crowd protests? Immediately after the tragic death of the Guatemalan girls, factual tweets created by media organisations flooded the Twittersphere in the form of messages informing the general population that something terrible has just happened. These factual tweets were followed by framing tweets. These framing tweets identified the victims (injustice tweets) and culprits (accusatory tweets). Now that the tragedy had been framed as a crime perpetrated against innocent girls by the state, SMOs, through mobilizer and motivational tweets, made calls to collective action to protest. The widely shared belief amongst the general public that an unprecedented injustice had been committed resulted in the mobilisation of thousands of Guatemalans onto the streets. Previous studies have demonstrated that when people can communicate effectively with one another, efforts at organizing a collective response are more likely to be successful (Oh et al. 2015; Shirky 2011; Starbird and Palen 2012). Our study contributes to the IS literature by explaining how social media, in this case, Twitter, enable the collective construction of meaning powerful enough to mobilize thousands through the creation of different types of content. 


\section{Conclusion}

Media decentralisation remains a pending task in many developing countries around the world in their way of building prosperous and genuine democracies (Blankson and Murphy 2012). In Latin America, since the return of civilian rule in the 1980 s and 1990s, the media has experienced substantial changes that have benefited mainly concentrated private interests at the expense of broader political and social goals (Fox and Waisbord 2002).

The developing countries account for the majority of the world's population and are important for this reason alone. A further reason to take the "majority world" seriously, from a business and policy perspective, is that the world is becoming increasingly interconnected in economic, social, and cultural terms (Walsham et al. 2007). When it comes to whether ICT is relevant to developing countries, "this debate has been resolved with a clear yes answer" (Walsham et al. 2007, p. 317). The question is not whether, but how ICT can benefit development.

There is broad consensus in the literature that improving the quality of democracy requires media organisations that can effectively monitor ruling political and economic powers (Blankson and Murphy 2012; Fox and Waisbord 2002; Rockwell and Janus 2001). When the advancing of business interests overshadows the public interest, and when the expectations of the powerful are deemed more important than the needs of citizens, the media are hardly a model of democratic virtue (Fox and Waisbord 2002). In Central America, the fact that some administrations have resorted to authoritarian means to suppress dissent and criticism adds more reason to worry about the prospects of bringing about an independent media (Rockwell and Janus 2001).

Despite ongoing monopolistic practices and oppressing tactics to crush critical views of those in power, ICT has become an alternative to renew the role of the media as watchdog on state institutions. In this study, we shed light on how ICT can make a difference in strengthening democracy by creating alternative spaces for a free press. Furthermore, the mobilisations mediated by ICT evidence efforts of a citizenry to forge a culture of zero tolerance towards negligence in the government and social injustice.

Of course, contribution is based on data from one event. Future studies could look at different events over a more extended period. Future research could also investigate how alternative media projects gain influence in public opinion. Such direction could shed light on how ICT serves as a platform for citizens in emerging democracies to become more engaged in their societies to affect change.

\section{References}

Atton, C. 2004. An Alternative Internet. New York: Columbia University Press.

BBC News. 2017. "Guatemala Children's Home Blaze Kills 19 Teenage Girls." BBC News Retrieved May 1, 2018, from http://www.bbc.com/news/world-latin-america-39208309

Benford, R. D., and Snow, D. A. 2000. "Framing Processes and Social Movements: An Overview and Assessment," Annual Review of Sociology (26:1), pp. 611-639.

Blankson, I. A., and Murphy, P. D. 2012. Negotiating Democracy: Media Transformations in Emerging Democracies. Suny Press.

Downing, J. 2001. Radical Media: Rebellious Communication and Social Movements. CA: Thousand Oaks.

Easley, D., and Kleinberg, J. 2010. Networks, Crowds, and Markets: Reasoning About a Highly Connected World. Cambridge: Cambridge University Press.

Flanagin, A. J., Stohl, C., and Bimber, B. 2006. "Modeling the Structure of Collective Action," Communication Monographs (73:1), pp. 29-54.

Fox, E., and Waisbord, S. 2002. Latin Politics, Global Media. University of Texas Press.

Fuchs, C. 2010. "Alternative Media as Critical Media," European Journal of Social Theory (13:2), pp. $173-192$.

Habermas, J. 1991. The Structural Transformation of the Public Sphere: An Inquiry into a Category of Bourgeois Society. MIT Press.

Harlow, S., and Harp, D. 2012. "Collective Action on the Web: A Cross-Cultural Study of Social Networking Sites and Online and Offline Activism in the United States and Latin America," Information, Communication \& Society (15:2), pp. 196-216.

Jürgens, P., and Jungherr, A. 2016. "A Tutorial for Using Twitter Data in the Social Sciences: Data Collection, Preparation, and Analysis," in: Preparation, and Analysis (January 5, 2016). Available at SSRN: https://ssrn.com/abstract=2710146.

Kendall, D. 2012. Sociology in Our Times. Cengage Learning. 
Kershaw, S. 2008. "A Different Way to Pay for the News You Want." The New York Times Retrieved July 2018,

from https://www.nytimes.com/2008/08/24/weekinreview/24kershaw.html

Klein, H. K., and Myers, M. D. 1999. "A Set of Principles for Conducting and Evaluating Interpretive Field Studies in Information Systems," MIS Quarterly: Management Information Systems (23:1), pp. 67-94.

Kunreuther, L. 2013. "Sounds of Democracy: Performance, Protest, and Political Subjectivity," Cultural Anthropology (27:3), pp. 1-31.

LeBrón, M. 2009. "Guatemala's Twitter Revolution," in: NACLA Report on the Americas New York: North American Congress on Latin America.

Leong, C., Pan, S. L., Bahri, S., and Fauzi, A. 2015. "Digital Enablement: Social Media in Empowering the Grassroot Environmental Movement of Malaysia," in: International Conference on Information Systems, ICIS.

Lievrouw, L. 2011. Alternative and Activist New Media. Malden, MA: Polity Press.

McKenna, B., Myers, M. D., and Newman, M. 2017. "Social Media in Qualitative Research: Challenges and Recommendations," Information and Organization (27:2), pp. 87-99.

Miranda, S. M., Young, A., and Yetgin, E. 2016. "Are Social Media Emancipatory or Hegemonic? Societal Effects of Mass Media Digitization," MIS Quarterly (40:2), pp. 303-329.

Oh, O., Agrawal, M., and Rao, H. R. 2013. "Community Intelligence and Social Media Services: A Rumor Theoretic Analysis of Tweets During Social Crises," MIS Quarterly (37:2), pp. 407-426.

Oh, O., Eom, C., and Rao, H. R. 2015. "Role of Social Media in Social Change: An Analysis of Collective Sense Making During the 2011 Egypt Revolution," Information Systems Research (26:1), pp. 210-223.

Pickard, V. W. 2008. "Cooptation and Cooperation: Institutional Exemplars of Democratic Internet Technology," New Media \& Society (10:4), pp. 625-645.

Rockwell, R. 2007. "Vestiges of Authoritarianism," in Negotiating Democracy: Media Transformations in Emerging Democracies. Albany: State University of New York Press, p. 35.

Rockwell, R., and Janus, N. 2001. "Stifling Dissent: The Fallout from a Mexican Media Invasion of Central America," Journalism Studies (2:4), pp. 497-512.

Selander, L., and Jarvenpaa, S. L. 2016. "Digital Action Repertoires and Transforming a Social Movement Organization," MIS Quarterly (40:2), pp. 331-352.

Shirky, C. 2011. "The Political Power of Social Media: Technology, the Public Sphere, and Political Change," Foreign Affairs), pp. 28-41.

Starbird, K., and Palen, L. 2012. "(How) Will the Revolution Be Retweeted?: Information Diffusion and the 2011 Egyptian Uprising," Proceedings of the ACM Conference on Computer Supported Cooperative Work: ACM, pp. 7-16.

Terchek, R. J. 1974. "Protest and Bargaining," Journal of Peace Research (11:2), pp. 133-144.

The New Yorker. 2017. "The Story Behind the Fire That Killed Forty Teen-Age Grils in a Guatemalan Children's Home." The New Yorker Retrieved May 1, 2018, from https://www.newyorker.com/news/news-desk/the-story-behind-the-fire-that-killedforty-teen-age-girls-in-a-guatemalan-childrens-home

Twitter. 2018. "Developer Agreement and Policy." Retrieved April 2018, from https://developer.twitter.com/en/developer-terms/agreement-and-policy

Waisbord, S. R. 1995. "Leviathan Dreams: State and Broadcasting in South America," The Communication Review (1:2), pp. 201-226.

Walsham, G., Robey, D., and Sahay, S. 2007. "Foreword: Special Issue on Information Systems in Developing Countries," MIS Quarterly), pp. 317-326.

Weick, K. E., Sutcliffe, K. M., and Obstfeld, D. 2005. "Organizing and the Process of Sensemaking," Organization Science (16:4), pp. 409-421.

Wolfson, T. 2012. "Book Review 2698-2700: Alternative and Activist New Media," International Journal of Communication (6).

Young, A. G. 2017. "Using Ict for Social Good: Cultural Identity Restoration through Emancipatory Pedagogy," Information Systems Journal (28:2), pp. 340-358. 